\title{
Methodology for the optimal design of transformerless grid-connected PV inverters
}

\author{
Eftichios Koutroulis ${ }^{1}$ and Frede Blaabjerg ${ }^{2}$ \\ ${ }^{1}$ Department of Electronic \& Computer Engineering, Technical University of Crete, \\ Chania, GR-73100, Greece, e-mail: efkout@electronics.tuc.gr \\ 2 Department of Energy Technology, Aalborg University, \\ Aalborg,DK-9220,Denmark, e-mail:fbl@et.aau.dk
}

\begin{abstract}
The transformerless PV inverters are the major functional units of modern grid-connected PV energy production systems. In this paper, a new optimization technique is presented for the calculation of the optimal types and values of the components comprising a transformerless PV inverter, such that the PV inverter Levelized Cost Of the generated Electricity (LCOE) is minimized. The proposed method constitutes a systematic design process, which is capable to explore the impact of the PV inverter configuration on the trade-off between the PV inverter manufacturing cost and the power losses affecting the corresponding energy production. The design optimization results demonstrate that the optimal values of the PV inverter design variables depend on the inverter specifications, the technical and economical characteristics of the components used to build the PV inverter and the meteorological conditions prevailing at the installation area. Compared to nonoptimized transformerless inverters, the PV inverter structures derived using the proposed design optimization methodology exhibit lower manufacturing cost and simultaneously are capable of producing more energy into the electric grid system.
\end{abstract}

Index Terms: Photovoltaic power systems, DC-AC power conversion, Design methodology, Optimization methods.

\section{Introduction}

The DC/AC inverters (PV inverters) are the key elements in grid-connected PV energy production systems, since they interface the energy produced by the PV array into the electric grid [1]. Compared to the grid-connected PV inverters with galvanic isolation, the transformerless PV inverters 
(e.g. full-bridge, NPC, HERIC etc.) have the advantages of lower cost, higher efficiency, smaller size and lower weight [1-3]. A general block diagram of a grid-connected PV system employing a transformerless PV inverter with a full-bridge power section is illustrated in Fig. 1. The power switches of the PV inverter are controlled by a control unit and an output filter is used to reduce the high-order harmonics, thus injecting a sinusoidal current into the electric grid.

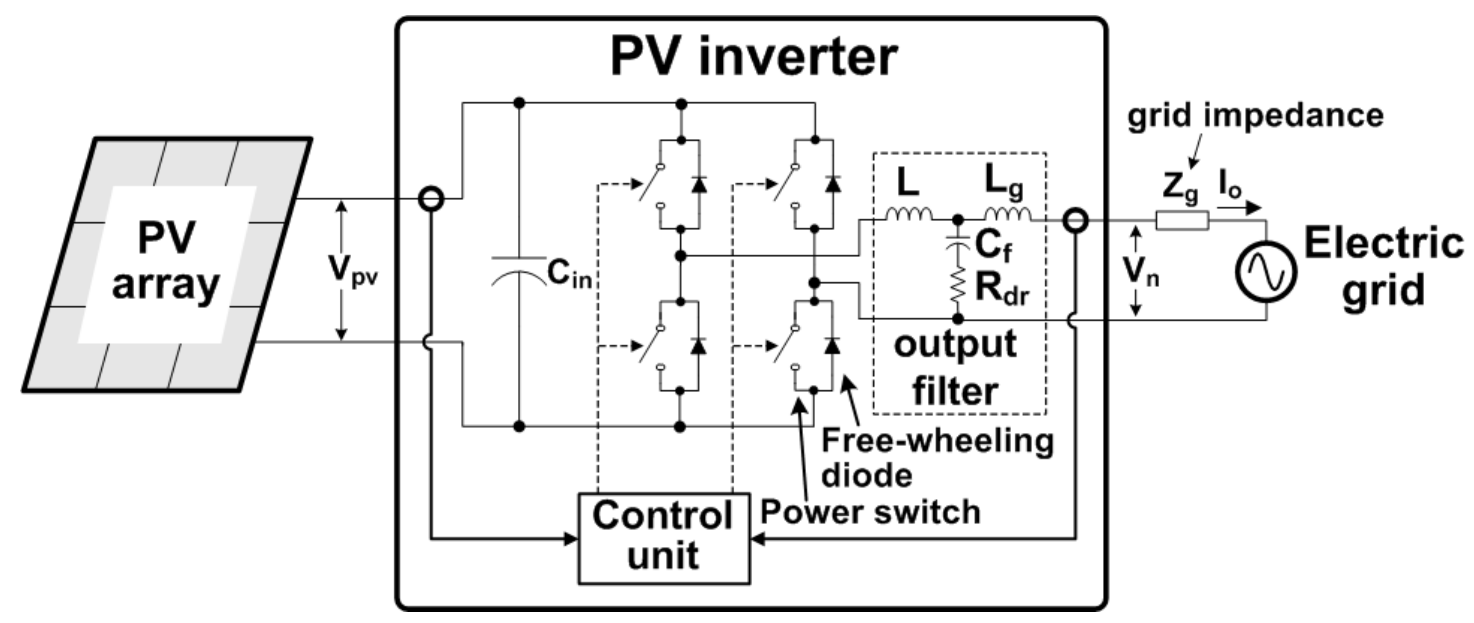

Fig. 1 A grid-connected PV system employing a transformerless single-phase PV inverter with a full-bridge power section.

The LCL-type output filters are usually used instead of the L- or LC-type filters, since they are capable to achieve attenuation of the switching harmonics using smaller reactive elements and also obtain better decoupling between the filter and the grid impedance [4]. The control unit developed is usually using DSP and FPGA ICs [5] for the execution of control and energy management algorithms (e.g. Maximum Power Point Tracking (MPPT) [6], modulation strategies [7] etc.), thus constituting a major subsystem of the PV inverter structure, affecting both the energy injected into the electric grid and the PV inverter cost. The optimal design of controller parameters, LC output filter components and the power sharing coefficients for enhancing the stability of an inverter-based micro-grid is presented in [8]. A technique for the design optimization of a one-cycle controller used in a single-stage inverter, by means of a multi-objective optimization strategy, is proposed in [9].

As analyzed in [10], the stochastically varying solar irradiation and ambient temperature conditions prevailing at the PV array installation site and the shape of the PV inverter efficiency vs. output power 
curves define the actual energy injected into the electric grid. An "ideal" PV inverter would be capable to maximize the energy injected into the electric grid with the minimum possible manufacturing cost. Typically, iterative trial-and-error techniques are employed in the design process of PV inverters, targeting to maximize performance metrics such as the power conversion efficiency at nominal operating conditions, or the "European Efficiency" [1, 11-13]. An optimal LCL-filter design procedure is proposed in [14] for the minimization of a PWM voltage-source converter output-filter cost and volume. The design process of the LCL-type output filter in a grid-interactive voltage-source inverter is explored in [15]. The total power loss of that filter is used as the optimization criterion for the selection of optimal values of the filter components. However, these methods have the disadvantage that the impact of the PV inverter component values and operational characteristics (e.g. maximum switching frequency) on both the PV inverter manufacturing cost and the total energy production is not considered during the design process.

In this paper, a new technique for the optimal design of the power section and output filter of transformerless PV inverters is presented. Using the proposed method, the optimal types and values of the PV inverter components are calculated such that the PV inverter Levelized Cost Of the generated Electricity (LCOE) is minimized, while simultaneously considering the limitations imposed by the electric-grid-interconnection regulations and international standards. Compared to the past-proposed approaches applied to design of PV inverters, the method presented in this paper has the advantage that the influences of the PV installation site solar irradiation potential, the PV array operational characteristics and the PV inverter component cost and operational characteristics, on both the PV inverter manufacturing cost and total energy production, are simultaneously taken into account during the PV inverter design process. Thus, the proposed design tool is capable to explore the impact of the PV inverter configuration (e.g. switching frequency applied, on-state voltage of the power switches etc.) on the trade-off between the PV inverter manufacturing cost and the power losses affecting the corresponding energy production. It comprises a systematic design process targeting to assist the PV inverter designer to derive the optimal PV inverter configuration, without significantly depending on the level of experience from the circuit designed. 
The proposed design optimization methodology is outlined in Section 2, the mathematical model considered during the optimization procedure is analyzed in Section 3 and a design optimization example is presented in Section 4. Finally, conclusions are drawn.

\section{The proposed design optimization methodology}

The target of the proposed design optimization methodology is to calculate the optimal values of the following PV inverter design variables:

- switching frequency, $f_{s}$,

- type of power semiconductors and

- values of output-filter inductances, $L$ and $L_{g}$, capacitance, $C_{f}$ and damping resistance, $R_{d r}$.

The optimization algorithm inputs are the following:

- operational characteristics and configuration (i.e. power rating, open-circuit voltage, number connected in series/parallel etc.) of the PV modules comprising the PV array connected to the PV inverter,

- 1-hour average solar irradiance and ambient temperature time-series during the year,

- PV inverter specifications (i.e. nominal output voltage/frequency and power rating) provided by the PV inverter designer,

- PV inverter topology and modulation strategy,

- price and technical characteristics of the power semiconductors comprising the PV inverter power section,

- price and technical characteristics of the magnetic components, capacitors and resistors of the output filter and

- specifications imposed by electric-grid-interconnection regulations (e.g. the maximum permitted harmonic-current level etc.).

The technical characteristics of the components used to construct the PV inverter are available in the device datasheet provided by the manufacturer, while their prices are specified by the market conditions. As in the past-proposed PV inverter design techniques, they are both considered as 
deterministic parameters in the proposed methodology. The solar irradiation and ambient temperature input data for each geographical location (e.g. based on yearly measurements, the typical meteorological year etc.) are widely available in databases of weather monitoring institutions, since they are also used to design and evaluate the performance of photovoltaic systems [16]. The operational characteristics and configuration of the PV modules and PV inverters comprising the gridconnected PV system are selected by the PV system designer using the techniques described in [17] for the maximization of the total revenues obtained during the lifetime operation (e.g. 25 years) of the PV installation. Similarly to these methods, the proposed design process of the PV inverter is performed without taking into account the probabilistic uncertainty associated with the meteorological input data [17].

The optimal values of the design variables are calculated such that the PV inverter Levelized Cost Of the generated Electricity ( $L C O E$, in $€ / \mathrm{kWh}$ ) [18] is minimized, while simultaneously the constraints imposed by the PV inverter specifications and electric-grid-interconnection regulations are met:

$$
\begin{aligned}
& \underset{\boldsymbol{m i n i m i z e}}{\operatorname{X}}\{L C O E\}=\underset{\boldsymbol{X}}{\operatorname{minimize}}\left\{\frac{C_{t}}{E_{t}}\right\} \\
& \text { subject to : } \\
& \quad \text { design specifications \& constraints are met }
\end{aligned}
$$

where $C_{t}(€)$ is the PV inverter total manufacturing cost, $E_{t}(\mathrm{kWh})$ is the PV inverter total output energy which is injected into the electric grid during the year and $\boldsymbol{X}$ is the vector of the design variables listed above.

For grid-connected PV installations it is desirable to maximize the net economic benefit obtained by selling the PV generated energy. This is achieved by minimizing the cost per unit energy injected into the electric grid for each individual subsystem of the PV installation (i.e. PV modules, inverters, balance of system components etc.). Thus, the use of $L C O E$, which involves both design and operational parameters, as an objective function in the proposed method enables to explore, during the design optimization process, the impact of the PV inverter configuration (e.g. switching frequency applied, on-state voltage of the power switches etc.) on the trade-off between the PV inverter 
manufacturing cost and the power losses affecting the corresponding energy production. The yearly energy injected by the PV inverter into the electric grid has been included in (1), since it has been considered that, similarly to the process used to design PV systems [17], the same yearly time-series of solar irradiation and ambient temperature conditions prevail during each year of the PV plant lifetime period.

In the proposed optimization process, hourly values of the meteorological input data are used to investigate the PV inverter operation during a time period of one year, for each set of the design variables values produced by the optimization algorithm. The management of the relatively high volume of meteorological input data required is easily achieved by developing the proposed optimization method in the form of a computer program as discussed later in this paper.

A flow-chart of the proposed optimization procedure is illustrated in Fig. 2. Given the PV inverter specifications and the electric and magnetic characteristics of the components, the violation of the PV inverter operational constraints is explored for each set of design variable values using the appropriate mathematical model of the PV inverter topology, which is under consideration. Then, the objective function of the design optimization process is evaluated. If any of the constraints is not satisfied or the global optimum of the objective function has not been derived, then a new set of the design variables values is produced by the optimization algorithm. This procedure is implemented using Genetic Algorithms (GAs), which are capable to derive the global optimum solution of complex non-linear objective functions with computational efficiency [19]. 


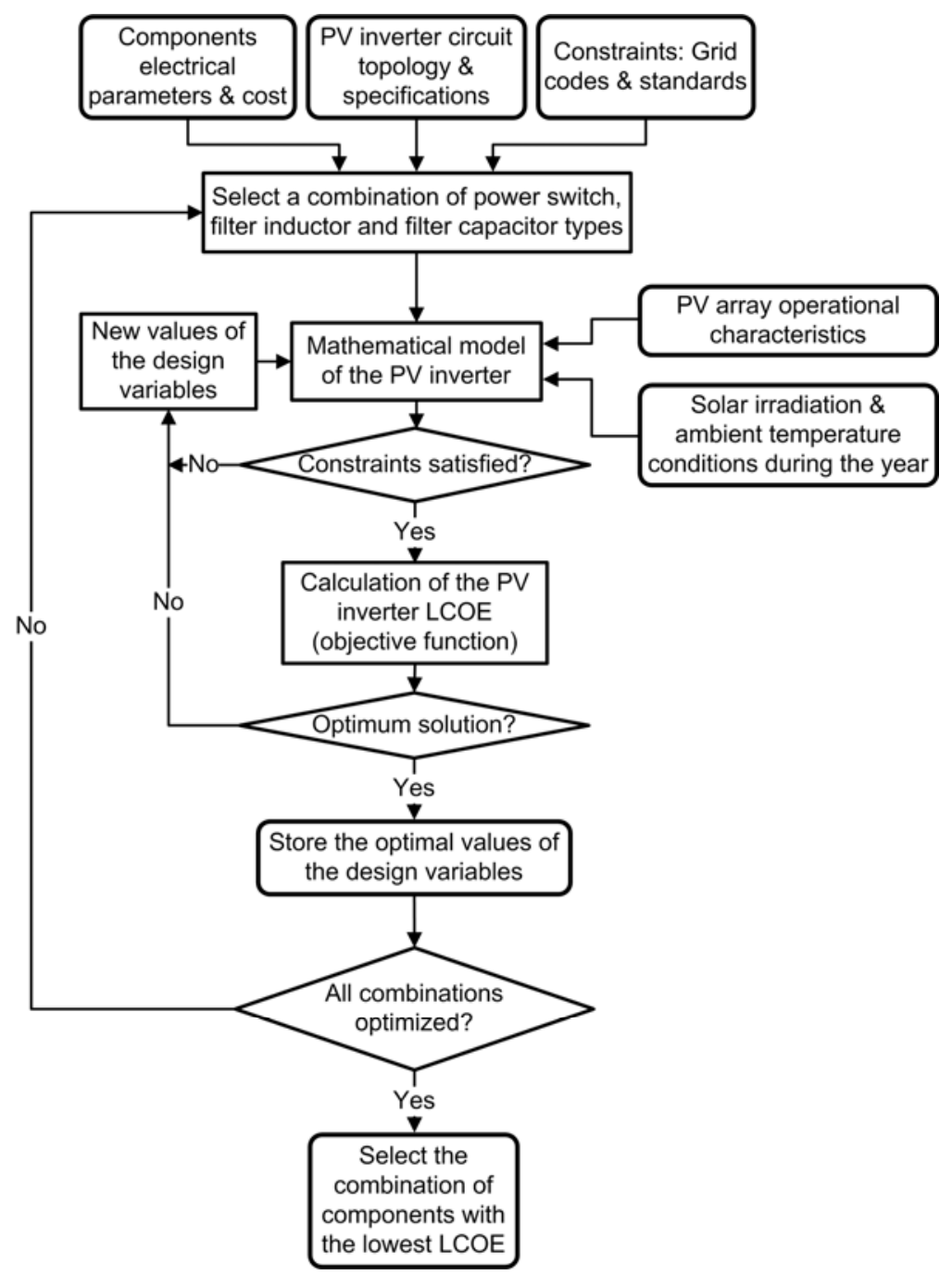

Fig. 2 A flow-chart of the proposed optimization procedure for grid-connected single-phase transformerless PV inverters.

The basic information unit of a GA-based optimization process is the chromosome, which corresponds to vector $\boldsymbol{X}$ in (1) and represents a potential solution of the optimization problem. A population of chromosomes is iteratively modified, thus producing the successive generations of the GA evolution process [19]. At each generation, the objective function is evaluated for all chromosomes of the corresponding population. The chromosome providing the lowest value of the objective function is comprised of the optimal design-parameter values of the PV inverter. This process is repeated until a predefined number of population generations have evolved.

After all combinations of component types input by the PV inverter designer have been optimally designed, the combination with the lowest $L C O E$ and the corresponding design variables values are 
output as the overall optimal design of the PV inverter. The values of $C_{t}$ and $E_{t}$ in (1) are calculated during the optimization procedure using the PV inverter model described in the following.

\section{PV inverter modeling for optimization}

The PV inverter input and output power levels are assumed constant during each one-hour time-step that the PV inverter operation is investigated during the year, as analyzed in $\S 2$. The power switches are controlled using the Sinusoidal Pulse Width Modulation (SPWM) principle [20]. The PV inverter output filter is considered to have the generalized LCL-type structure illustrated in Fig. 1, consisting of the components $L, L_{g}, C_{f}$ and $R_{d r}$. In case that the PV inverter designer specifies that the PV inverter comprises an L- or LC-type filter, then the values of $\left[L_{g}, C_{f}, R_{d r}\right]$ or $\left[L_{g}, R_{d r}\right]$, respectively, are set equal to zero during the optimization process.

The ripple factor, $R F_{\mathrm{sw}}(\%)$, which is due to the converter-side inductance only, $L$, is constrained to be less than the maximum permissible limit, $R F_{s w, m}(\%)[21]$ :

$$
R F_{s w}=\frac{I_{r}(t) V_{n}}{P_{n}} \leq R F_{s w, m}
$$

where $I_{r}(t)$ (A) is the RMS value of the switching ripple due to the converter-side inductance, $L$, at hour $t(1 \leq t \leq 8760), V_{n}(\mathrm{~V})$ is the PV inverter nominal output voltage $(\mathrm{V})$ and $P_{n}(\mathrm{~W})$ is the PV inverter nominal output power level.

The value of $R F_{s w, m}$ is input to the proposed optimization process by the PV inverter designer and it is typically selected in the range of $10-25 \%[21,22]$. The value of $R F_{\mathrm{sw}}$ affects the value and size of the converter-side inductance, $L$. The $L_{g}-C_{f}$ part of the LCL-filter will further reduce the current ripple at the PV inverter output, as analyzed next.

In case of a full-bridge SPWM inverter (Fig. 1) producing a unipolar output voltage waveform and operating with one fast-switching leg and a slow-switching leg (i.e. $50 \mathrm{~Hz}$ ), the value of $I_{r}$ is calculated as follows [23]: 


$$
I_{r}=\frac{V_{p v}(t) \cdot \sqrt{\frac{2 m_{\mathrm{a}}^{2}\left[\frac{\pi}{4}\left(1+\frac{3 m_{\mathrm{a}}^{2}}{4}\right)-4 \frac{m_{\mathrm{a}}}{3}\right]}{3 \pi}}}{2 L f_{s}}
$$

where $V_{p v}(t, y)(\mathrm{V})$ is the PV array output voltage under MPPT conditions at hour $t(1 \leq t \leq 8760), m_{\mathrm{a}}$ is the modulation index and $f_{s}(\mathrm{~Hz})$ is the switching frequency of the fast-switching leg.

The value of $m_{\mathrm{a}}$ is given by:

$$
m_{\mathrm{a}}=\frac{\sqrt{2 \cdot\left\{V_{n}^{2}+\left[I_{o}(t) 2 \pi f\left(L+L_{g}\right)\right]^{2}\right\}}}{V_{p v}(t)}
$$

where $I_{o}(t)(\mathrm{A})$ is the RMS PV inverter output current at hour $t(1 \leq t \leq 8760)$, calculated as analyzed below and $f(\mathrm{~Hz})$ is the $\mathrm{PV}$ inverter nominal output frequency.

Depending on the type of the PV inverter output filter specified by the PV inverter designer:

- L- or LC-type output filter: the value of $R F_{s w, m}$ in (2) is equal to the maximum permissible limit, $R F_{\max }(\%)$,

- LCL-type output filter: the $L_{g}-C_{f}$ part of the filter is designed such that the current ripple which is due to the converter-side inductance only, $R F_{\mathrm{sw}}$ in $(2)$, is further reduced below $R F_{\max }(\%)$ at the PV inverter output:

$$
R F=R F_{s w} \cdot R_{a} \leq R F_{\max }
$$

where $R F(\%)$ is the ripple factor at the PV inverter output, $R_{a}(\%)$ is the ripple attenuation factor of the LCL filter evaluated at the switching frequency and $R F_{\max }(\%)$ is the maximum permissible limit of harmonic current distortion at the PV inverter output.

The value of $R_{a}(\%)$ is calculated according to [21] as follows:

$$
R_{a}=\frac{i_{g}\left(h_{s}\right)}{i\left(h_{s}\right)}=\frac{K_{d}}{\left|1+\frac{L_{g}}{L} \cdot\left(1-L C_{b} \omega_{s}^{2} \frac{C_{f}}{C_{b}}\right)\right|}
$$


where $h_{s}$ is the order of the switching frequency harmonic, $i_{g}\left(h_{s}\right)$ and $i\left(h_{s}\right)$ are the grid- and converter-side currents, respectively, at the switching frequency, $K_{d}$ is a factor accounting for the reduction in filter effectiveness due to damping, $C_{b}$ is the base capacitance $\left[C_{b}=P_{n} /\left(V_{n}^{2} 2 \pi f\right)\right]$ and $\omega_{s}=2 \pi f_{s}$. Additionally, in order to ensure that resonance problems in the lower and upper parts of the harmonic spectrum are avoided, the LCL-filter resonant frequency, $f_{\text {res }}(\mathrm{Hz})$, is selected as follows:

$$
10 \cdot f \leq f_{\text {res }} \leq \frac{f_{s}}{2}
$$

where $f_{\text {res }}=\frac{1}{2 \pi} \cdot \sqrt{\left(L+L_{g}\right) / L_{g} C_{f} L}$.

The value of $R F_{\max }$ is selected such that the current ripple at the PV inverter output is reduced at an acceptable level, in order to comply with the limits imposed by grid regulations and international standards (e.g. IEEE-519, IEEE-1547 etc.) [14].

The total value of the PV inverter output filter inductance is restricted to be less than $0.1 \mathrm{pu}$ in order to limit the AC voltage drop during operation, thus enhancing the dynamic response of the PV inverter $[4,21]:$

$$
L+L_{g} \leq 0.1 \cdot L_{b}
$$

where $L_{b}$ is the base inductance $\left[L_{b}=V_{n}^{2} /\left(P_{n} 2 \pi f\right)\right]$.

In order to limit the power loss due to reactive current circulation, the value of the LC- or LCL-filter capacitor, $C_{f}$, is selected such that its reactive power is less than $5 \%$ of the rated power:

$$
C_{f} \leq 0.05 \cdot C_{b}
$$

In the case of an LCL-type output filter, the damping resistor value, $R_{d r}(\Omega)$, is set equal to the filter capacitor impedance at the resonant frequency, otherwise it is set equal to zero:

$$
R_{d r}=\left\{\begin{array}{l}
\frac{1}{C_{f} 2 \pi f_{r e s}} \text { for LCL-type filter } \\
0 \quad \text { for L-or LC-type filters }
\end{array}\right.
$$


The design process of the PV inverter is performed assuming that the electric grid operates under nominal frequency (i.e. $50 \mathrm{~Hz}$ ) conditions $[21,23]$. Since the SPWM principle is applied in order to control the power switches, the PV inverter switching frequency, $f_{s}$, is constrained to be an integer multiple of the nominal grid frequency, $f(\mathrm{~Hz})$. Additionally, the maximum possible value of $f_{s}$ is dictated by the maximum switching-speed capability of the power switches, $f_{s, \max }(\mathrm{Hz})$, specified by their manufacturer:

$$
f_{s} \leq f_{s, \max }
$$

It is assumed that an efficient MPPT is performed by the PV inverter control unit, such that the maximum available PV power is supplied to the PV inverter [6]. The total energy injected into the electric grid by the PV inverter during the year, $E_{t}(\mathrm{Wh})$, is calculated from a power-balance equation as follows:

$$
E_{t}=\sum_{t=1}^{8760} P_{o}(t) \cdot \Delta t=\sum_{t=1}^{8760}\left[P_{p v}(t)-P_{l}(t)\right] \cdot \Delta t
$$

where $P_{o}(t), P_{p v}(t)$ and $P_{l}(t)(\mathrm{W})$ is the power injected into the grid by the PV inverter, the PV array output power under MPPT conditions and the PV inverter total power loss, respectively, at hour $t$ $(1 \leq t \leq 8760)$ and $\Delta t$ is the simulation time-step ( $\Delta t=1$ hour $)$.

The PV inverter total power loss, $P_{l}$ (W), is equal to the sum of the power losses of the individual components and sub-systems comprising the PV inverter:

$$
P_{l}(t)=P_{c o n d}+P_{s w}+P_{d}+P_{L, c}+P_{L, r}+P_{c u}
$$

where $P_{\text {cond }}$ and $P_{s w}(\mathrm{~W})$ are the power section switches and diodes total conduction and switching losses, respectively, $P_{d}(\mathrm{~W})$ is the power loss on the LCL-filter damping resistor, $P_{L, c}$ and $P_{L, r}(\mathrm{~W})$ are the LCL-filter inductors total core and winding losses, respectively and $P_{c u}(\mathrm{~W})$ is the power consumption of the control unit (due to the circuits of the SPWM modulator, power switch drivers, sensors and signal conditioners etc.) and cooling system. 
In (13), the power semiconductor conduction and switching losses, $P_{c o n d}$ and $P_{s w}$ respectively, are calculated as the sum of the conduction and switching losses of the individual power switches and diodes forming the power section of the PV inverter. For the calculation of the power semiconductor conduction losses, $P_{\text {cond }}$, the PV inverter power switches and diodes are considered as voltage sources with resistors connected in series [24]:

$$
\begin{aligned}
& V_{s}=V_{s, o n}+I_{s} \cdot R_{s, o n} \\
& V_{d}=V_{d, f}+I_{d} \cdot R_{d, f}
\end{aligned}
$$

where $V_{s}, V_{d}(\mathrm{~V})$ are the voltage drop across the power switch and diode, respectively, $I_{s}, I_{d}(\mathrm{~A})$ are the conduction current of the power switch and diode, $V_{s, o n}(\mathrm{~V}), R_{s, o n}(\Omega)$ are the power switch onstate voltage and resistance and $V_{d, f}(\mathrm{~V}), R_{d, f}(\Omega)$ are the diode forward voltage and resistance.

The average power loss during conduction of each power switch and diode of the PV inverter, $P_{s}$ and $P_{d}(\mathrm{~W})$, is then calculated based on (14) and (15), according to the following equations:

$$
\begin{aligned}
& P_{s}=V_{s, o n} \cdot I_{s, a v g}+I_{s, r m s}^{2} \cdot R_{s, o n} \\
& P_{d}=V_{d, f} \cdot I_{d, a v g}+I_{d, r m s}^{2} \cdot R_{d, f}
\end{aligned}
$$

where $I_{s, a v g}, I_{d, a v g}$ (A) are the average values of the power switch and diode current, respectively and $I_{s, r m s}, I_{d, r m s}(\mathrm{~A})$ are the RMS values of the power switch and diode current, respectively.

The values of $I_{s, a v g}, I_{d, a v g}, I_{s, r m s}$ and $I_{d, r m s}$ in (16) and (17) depend on the PV inverter power section topology (e.g. full-bridge, H5 etc.) under consideration. The switching losses in (13), $P_{s w}$, are equal to the sum of the power switches turn-on and turn-off losses as well as the reverse recovery losses of the power diodes. They are calculated to be proportional to the switching frequency, $f_{s}$, the turn-on and turn-off energy, $E_{\text {on }}$ (Joule) and $E_{\text {off }}$ (Joule), respectively and the peak load current of the PV inverter, as analyzed in [24]. The values of $V_{s, o n}, R_{s, o n}, V_{d, f}, R_{d, f}, E_{o n}$ and $E_{o f f}$ are specified by the power semiconductor manufacturer and they are input to the proposed optimization process by the PV inverter designer. 
The power loss on the LCL-filter damping resistor, $P_{d}(\mathrm{~W})$, depends on the RMS current of the damping resistor, $I_{d r, r m s}(\mathrm{~A})$ :

$$
P_{d}(t)=I_{d r, r m s}^{2} \cdot R_{d r}=\left[\frac{V_{n}^{2}+\left[I_{o}(t) 2 \pi f L_{g}\right]^{2}}{\left(1 / 2 \pi f C_{f}\right)^{2}+R_{d r}^{2}}+I_{r}^{2}(t)\right] \cdot R_{d r}
$$

where $R_{d r}(\Omega)$ is the damping resistor value.

The total core losses of the LCL-filter inductors, $P_{L, c}(\mathrm{~W})$, are calculated according to [25], while simultaneously considering that the optimization process guarantees the satisfaction of (5) which permits to neglect the high-frequency current ripple flowing through the filter inductor $L_{g}[21]$ :

$$
P_{L, c}(t)=k_{f} m_{a}^{-a}\left(f_{s} / 1000\right)^{-b} p_{c-l} L \cdot\left[I_{o}(t) \cdot \sqrt{2 L}\right]^{c}+p_{c-l} L_{g} \cdot\left[I_{o}(t) \cdot \sqrt{2 L_{g}}\right]^{c}
$$

where $k_{f}$ is a constant expressing the impact of the non-sinusoidal excitation, PWM modulation index, switching frequency and inductor volume, respectively, on the inductor core loss, $a, b$ and $c$ are constants dependent on the inductor core material and $p_{c-l}$ is the inductor core-loss factor under sinusoidal excitation $\left(W /\left[H \cdot(\sqrt{H} \cdot A)^{c}\right]\right)$.

The total power loss on the windings of the LCL-filter inductors, $P_{L, r}(\mathrm{~W})$, is calculated according to the RMS current of each inductor, as follows:

$$
P_{L, r}(t)=I_{r}^{2}(t) r_{l} L+I_{o}^{2}(t) r_{l}\left(L+L_{g}\right)
$$

where $r_{l}(\Omega / \mathrm{H})$ is the winding resistance of the inductances normalized per unit inductance.

The values of $c, p_{c-l}$ and $r_{l}$ in (18)-(20) are specified by the inductor manufacturer. The parameters $k_{f}, a$ and $b$ are estimated according to the procedure described in [25] and their values, together with those of $c, p_{c-l}$ and $r_{l}$, are input in the proposed optimization process by the PV inverter designer.

The power loss models presented above have been considered in the proposed methodology because of their simplicity. Since the optimization process is modular, the proposed methodology can also be applied for the design optimization of any PV inverter topology (e.g. NPC, Active-NPC etc.) if the 
appropriate power-loss models (e.g. those presented in [2] and [26]) are used to calculate the conduction and switching losses of the power semiconductors employed in that topology.

The PV inverter output current, $I_{o}(t)(\mathrm{A})$, is calculated using a numerical analysis method from the power-balance equation:

$$
P_{p v}(t)=P_{l}(t)+V_{n} I_{o}(t)
$$

The values of $V_{p v}$ and $P_{p v}$ in (3), (4), (12) and (21) are calculated on an hourly basis during the year using the PV modules model analyzed in [27], based on the solar irradiation and ambient temperature time-series, the electrical specifications of the PV modules and their configuration (i.e. connection in series and parallel) within the PV array, which are input in the proposed optimization procedure by the PV inverter designer.

The total manufacturing cost of the PV inverter, $C_{t}(€)$, is equal to the sum of the prices of the components comprising the PV inverter:

$$
C_{t}=c_{i n v} P_{n}+n_{s} c_{s}+n_{d} c_{d}+c_{i} \cdot\left(L+L_{g}\right) \frac{P_{n}}{V_{n}}+c_{c} C_{f}+S F \cdot c_{r} R_{d r} P_{d, \max }
$$

where $c_{i n v}(€ / \mathrm{W})$ is the PV inverter manufacturing cost, comprising the costs of labor and raw materials, without including the cost of the power switches, diodes and output filter components (e.g. control unit, heat-sinks, printed circuit boards etc.), $n_{s}, n_{d}$ are the number of power switches and diodes, respectively, comprising the PV inverter power section, $c_{s}, c_{d}(€)$ are the cost of each power switch and diode, respectively, $c_{i}[€ /(H \cdot A)]$ is the filter inductors cost per unit inductance and current rating, $c_{c}(€ / F)$ is the filter capacitor cost per unit capacitance, $c_{r}[€ /(\Omega \cdot W)]$ is the filter damping resistor cost per unit resistance and power, $S F(\%)$ is the damping resistor over-sizing factor and $P_{d, \max }(\mathrm{W})$ is the maximum power dissipated on the damping resistor during the year.

The value of $P_{d, \max }$ is calculated based on the damping resistor power loss during the year given by (18), as follows:

$$
P_{d, \max }=\underset{1 \leq t \leq 8760}{\max }\left\{P_{d}(t)\right\}
$$


In the proposed methodology, the PV inverter design process described in $\S 2$ is performed by calculating the values of $E_{t}$ and $C_{t}$ in (1) using (12) and (22) and simultaneously it is subject to the constraints defined by inequalities (2), (5), (7)-(9) and (11).

\section{Design optimization example}

The proposed methodology has been applied for the optimal design of a transformerless singlephase/full-bridge PV inverter interconnected with the electric grid (Fig. 1) with $P_{n}=2000 \mathrm{~W}$, $V_{n}=220 \mathrm{~V}$ and $f=50 \mathrm{~Hz}$. The power switches are controlled according to the unipolar SPWM modulation strategy with one fast-switching leg and a slow-switching leg. The PV inverter under study is connected to a PV array composed of $12 \mathrm{PV}$-modules connected in series (total area $=15 \mathrm{~m}^{2}$ ). The Maximum Power Point (MPP) power and voltage ratings of each PV-module, under Standard Test Conditions (STC), are $175 \mathrm{~W}$ and $35.4 \mathrm{~V}$, respectively.

The decision variables considered during the design optimization procedure are the PV inverter power semiconductors type, the switching frequency and the values of the LCL-filter components. Thus, in the proposed optimization methodology each GA chromosome corresponds to vector $\boldsymbol{X}$ in (1) and consists of four genes (i.e. $L, L_{g}, C_{f}$ and $f_{s}$ ) in the form: $\boldsymbol{X}=\left[L\left|L_{g}\right| C_{f} \mid f_{s}\right]$. After the GA-based optimization process described in $\S 2$ has been accomplished, the optimal value of the LCLfilter damping resistor, $R_{d r}$, is calculated according to (10) using the resulting optimal values of $L, L_{g}$ and $C_{f}$. The values of $P_{\text {cond }}$ and $P_{s w}$ in (13) have been calculated using the equations of the power-loss model presented in [24] as a function of $L, L_{g}, f_{s}, V_{n}, f, I_{o}(t), V_{p v}(t)$ and the conduction and switching operational characteristics of the power switches and free-wheeling diodes under consideration, specified by their manufacturer. The maximum permissible output current ripple has been set to $R F_{\max }=4 \%$ in order to comply with the IEEE-1547 standard, while the maximum limit of the ripple factor due to the converter-side inductance only has been set to $R F_{s w, m}=20 \%$ according to $[21,22]$. 
Two different types of IGBT-type power switches with free-wheeling diodes are considered as potential alternatives for incorporation in the PV inverter power section. As analyzed in $\S 2$, the proposed optimization process is separately performed for each of these two types in order to derive the overall optimum configuration. In this design optimization example, it is assumed that the power semiconductors are mounted on heat sinks with convection cooling, thus the cooling system does not consume any power. The technical characteristics of commercially available power switches and freewheeling diodes considered in this design optimization example are presented in Table 1 . In the technical characteristics of the LCL output filter inductors shown in Table 2, the values of $k_{f} a, b, c$ and $p_{c-l}$ have been extracted from $[15,28]$, while that of $r_{l}$ is based on the corresponding values of commercially available power inductors. The filter effectiveness due to damping is reduced by $K_{d}=1.57$ [21] and the damping resistor over-sizing factor has been empirically set equal to $S F=110 \%$. Similarly to commercially available PV inverters of the same power rating, the control unit power consumption has been set equal to $P_{c u}=5 \mathrm{~W}$. The economical characteristics of the PV inverter components considered in the optimization process are based on the selling prices of the corresponding components in the international market and they are tabulated in Table 3. Considering the cost of PV inverters in $[29,30]$ as well as after conducting a survey of the international market, the value of $c_{i n v}$ in (22) has been set equal to $355 € / \mathrm{kW}$.

Table 1 The technical characteristics of the PV inverter power switches and free-wheeling diodes

\begin{tabular}{cccccccc}
\hline & $V_{\text {s,on }}(\mathrm{V})$ & $R_{s, \text { on }}(\mathrm{m} \Omega)$ & $V_{d, f}(\mathrm{~V})$ & $R_{d, f}(\mathrm{~m} \Omega)$ & $E_{\text {on }}(\mathrm{mJ})$ & $E_{\text {off }}(\mathrm{mJ})$ & $f_{s, \max }(\mathrm{kHz})$ \\
\hline Type 1 & 0.75 & 83.3 & 0.87 & 120 & 0.09 & 0.11 & 30 \\
\hline Type 2 & 1.05 & 37.1 & 1.1 & 47 & 0.58 & 0.25 & 80 \\
\hline
\end{tabular}

Table 2 The technical characteristics of the LCL output filter inductors of the PV inverter

\begin{tabular}{cccccc}
\hline$k_{f}$ & $\alpha$ & $b$ & $c$ & $p_{c-l}$ & $r_{l}(\Omega / \mathrm{H})$ \\
\hline 5.42 & 1.21 & 0.09 & 0.058 & 1747 & 8 \\
\hline
\end{tabular}


Table 3 The economical characteristics of the PV inverter components

\begin{tabular}{ccccc}
\hline$c_{\text {inv }}(€ / \mathrm{kW})$ & $c_{s}+c_{d}(€)$ & $c_{i}[€ /(H \cdot A)]$ & $c_{c}(€ / \mathrm{F})$ & $c_{r}[€ /(\Omega \cdot W)]$ \\
\hline \multirow{3}{*}{355} & Type 1: & & & \\
\cline { 2 - 2 } & 1.5 & 832 & $134 \times 10^{3}$ & $3.6 \times 10^{-3}$ \\
& Type 2: & & & \\
\hline
\end{tabular}

A software program operating under the MATLAB platform has been developed in order to implement the proposed design tool. The Genetic Algorithm functions available in the library of the MATLAB Global Optimization Toolbox have been used to develop the GA-based evolution program in order to derive the global minimum of the PV inverter LCOE function. The GA process has been executed for $\mathrm{G}=200$ generations with $\mathrm{N}=70$ chromosomes in each generation.

The optimal values of the PV inverter LCL output filter components $\left(L, L_{g}, C_{f}\right.$ and $\left.R_{d r}\right)$, switching frequency, $f_{s}$ and $L C O E$, calculated using the proposed optimization technique for the two alternative types of power switches in the case of PV inverters installed at various sites in Europe, are summarized in Table 4. A different set of optimal values of the PV inverter design variables is derived in each case, since each installation site is characterized by different solar irradiation and ambient temperature conditions.

Table 4 The optimal values of the PV inverter design variables and LCOE for various installation sites in Europe

\begin{tabular}{cccccccc}
\hline & $\begin{array}{c}\text { Power } \\
\text { switch }\end{array}$ & $\begin{array}{c}L \\
(\mathrm{mH})\end{array}$ & $\begin{array}{c}L_{g} \\
(\mu \mathrm{H})\end{array}$ & $\begin{array}{c}C_{f} \\
(\mu \mathrm{F})\end{array}$ & $\begin{array}{c}R_{d r} \\
(\Omega)\end{array}$ & $\begin{array}{c}f_{s} \\
(\mathrm{kHz})\end{array}$ & $\begin{array}{c}L C O E \\
(€ / \mathrm{kWh})\end{array}$ \\
\hline \multirow{2}{*}{$\begin{array}{c}\text { Athens } \\
\text { (Greece) }\end{array}$} & Type 1 & 1.459 & 48.121 & 5.608 & 2.882 & 28.85 & 0.223 \\
\cline { 2 - 7 } & Type 2 & 1.361 & 39.508 & 5.661 & 2.604 & 31.45 & 0.225 \\
\hline $\begin{array}{c}\text { Murcia } \\
\text { (Spain) }\end{array}$ & Type 1 & 1.682 & 59.610 & 5.906 & 3.122 & 25.10 & 0.198 \\
\hline & Type 2 & 0.873 & 19.189 & 5.154 & 1.909 & 47.65 & 0.198 \\
\hline $\begin{array}{c}\text { Freiburg } \\
(\text { Germany) }\end{array}$ & Type 1 & 1.463 & 43.651 & 5.921 & 2.676 & 29.50 & 0.323 \\
\hline \multirow{2}{*}{$\begin{array}{c}\text { Oslo } \\
\text { (Norway) }\end{array}$} & Type 2 & 1.519 & 48.172 & 5.209 & 2.994 & 29.45 & 0.327 \\
\cline { 2 - 8 } & Type 1 & 1.557 & 38.272 & 6.577 & 2.383 & 29.55 & 0.328 \\
\hline
\end{tabular}


The two types of power switches achieve equivalent performance in terms of PV inverter $L C O E$ in Murcia (Spain). In the rest of the installation sites considered, the minimum $L C O E$ is obtained using the power switch type \#1, because although of lower switching-speed capability compared to power switch type \#2, it exhibits lower on-state voltage and cost, which better match the PV array energy production at these sites. In all cases examined, the optimal switching frequency of PV inverters built using power switch type $\# 1$ has been calculated to be near to the maximum permissible value imposed by the power switch operational capabilities, thus aiming towards the reduction of the output filter size and cost. The optimal design results presented in Table 4 indicate that the LCL-filter is the optimal output filter type for the installation sites considered, since in the case that an L or LC-type filter was more appropriate, then the optimal values of $L_{g}$ and/or $C_{f}$ derived by applying the proposed optimization process would be calculated to approach zero. The optimal LCOEs for each installation site deviate by less than $1.24 \%$, while the corresponding deviations between the optimal values of the design variables are in the range of 0.17-89.4\%. Since the objective function is characterized by such a low sensitivity close to each optimal solution, in case that under practical operating conditions the design parameters $L, L_{g}, C_{f}$ and $R_{d r}$ deviate from the optimal values presented in Table 4, the resulting deviation of the PV inverter LCOE will practically be negligible.

The optimal values of $L C O E$ and total energy injected into the electric grid during the year [i.e. $E_{t}$ in (1) and (12)] for each installation site of the optimized PV inverter comprising the type \#1 power switches, are illustrated in Figs. 3(a) and (b), respectively. The minimum optimal LCOE is achieved in Murcia (Spain) although, compared to the rest optimized PV inverter structures, the corresponding optimal cost of the PV inverter is higher in this case (Fig. 4). This is due to the high availability of solar irradiation at that area, which results in increased energy to be injected into the electric grid by the optimized PV system. In case that the PV inverter optimized for Murcia (Spain) is installed in either Athens (Greece), Freiburg (Germany) or Oslo (Norway), then the PV inverter output current ripple constraint of the optimization process, expressed by the inequality in (5), is violated. 


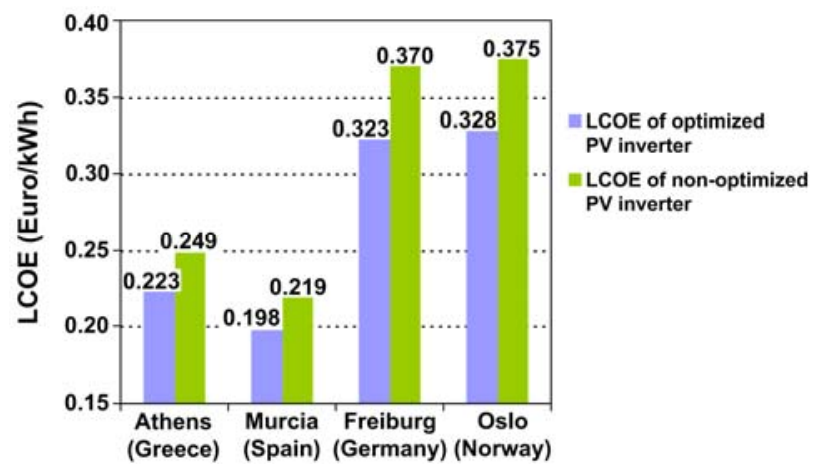

(a)

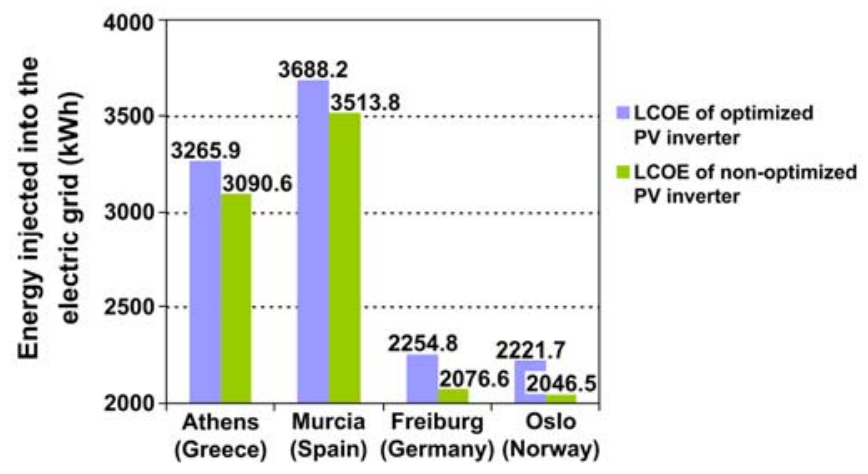

(b)

Fig. 3 The optimized and non-optimized PV inverters for various installation sites in Europe: (a) LCOE and (b) yearly energy injected into the electric grid for 12 PV modules (total area $=15 \mathrm{~m}^{2}$ ).

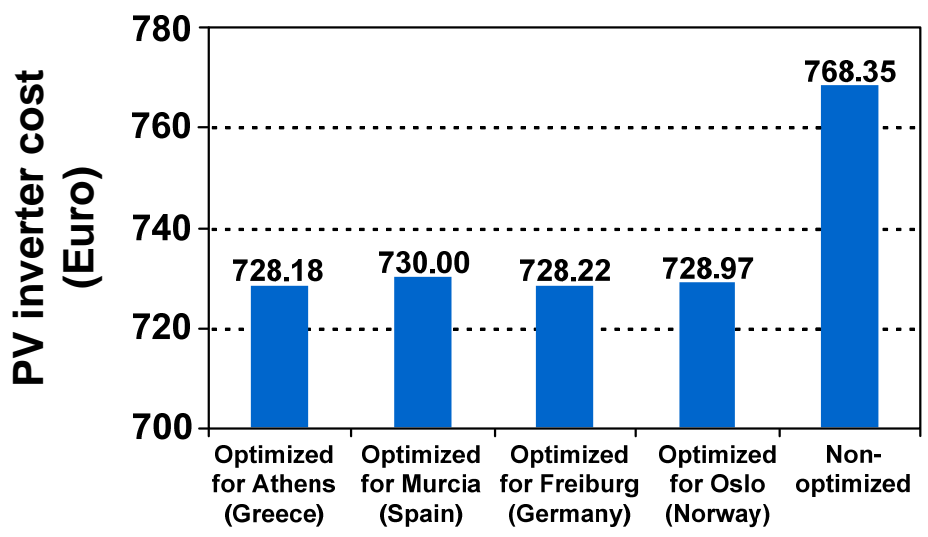

Fig. 4 The cost of PV inverters optimized for various installation sites and the cost of the nonoptimized PV inverter.

The $L C O E$ and yearly energy production of a non-optimized PV inverter comprised of type \#1 power switches and operating at $f_{s}=8 \mathrm{kHz}$, which is a typical switching frequency value in this power range $[1,2]$, are also depicted in Fig. 3. The non-optimized PV inverter is comprised of an LCL output filter, which has been designed as analyzed in [21] with $L=5.65 \mathrm{mH}, L_{g}=1.09 \mathrm{mH}$, $C_{f}=3.29 \mu \mathrm{F}$ and $R_{d r}=5.6 \Omega$. Thus, the non-optimized PV inverter has been designed without considering the manufacturing cost and yearly energy production. Compared to the non-optimized PV inverter, using the proposed design method the optimized PV inverter $L C O E$ is reduced by $9.6-12.7 \%$ and the PV-generated energy injected into the electric grid is increased by $4.9-8.6 \%$. 
As illustrated in Fig. 4, the cost of the optimized PV inverters depends on the installation site, while, additionally, the non-optimized PV inverter cost is higher by 5.3-5.5\%. Depending on the installation site, the efficiency at maximum AC power and the European efficiency of the optimized PV inverters comprising the type \#1 power switches vary in the range 96.69-96.73\% and $94.71-94.99 \%$, respectively (Fig. 5). The corresponding values of the non-optimized PV inverter are lower by 2.50$2.54 \%$ and 6.92-7.20\%, respectively. Although the lowest efficiency at maximum AC power and European efficiency values have been obtained for the PV inverter optimized for Murcia (Spain), as demonstrated in Fig. 3 that inverter also exhibits the lowest $L C O E$ value. Efficiencies of the same level have also been reported in [1] for commercially available non-optimized transformerless PV inverters, which, however, have not been designed considering the manufacturing cost / energy production trade-off.

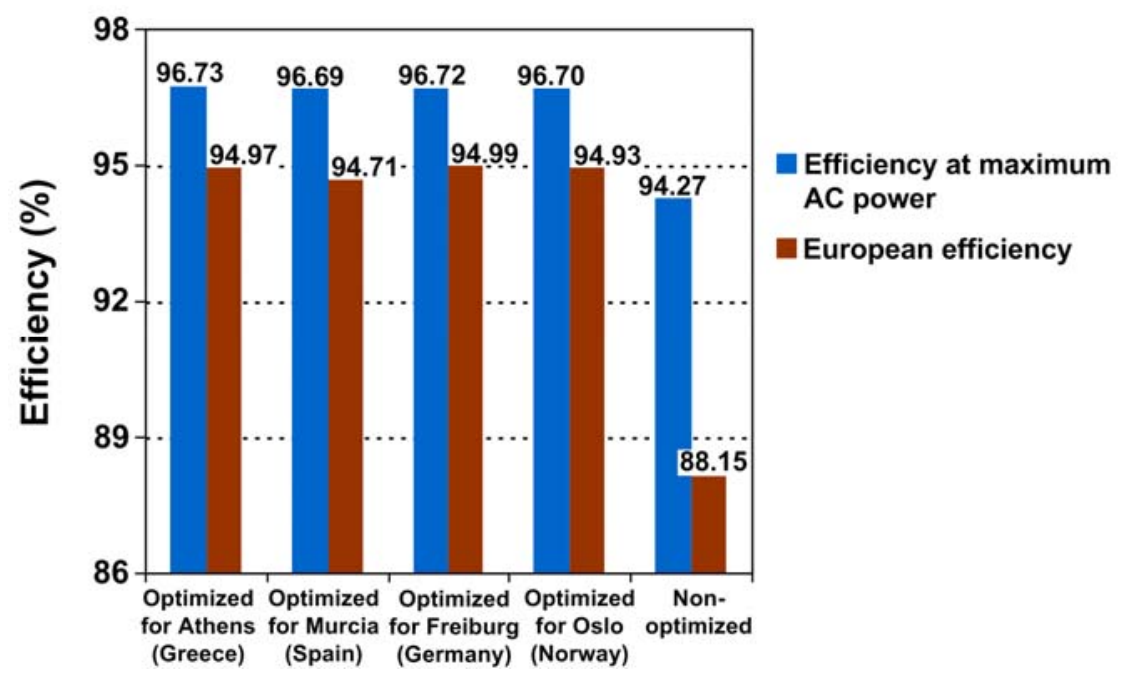

Fig. 5 The efficiency at maximum AC power and European efficiency of PV inverters optimized for various installation sites in Europe and of the non-optimized PV inverter.

In order to demonstrate an example of the optimization problem search-space, the plot of the PV inverter $L C O E$ versus the decision variables $C_{f}$ and $L_{g}$, in case that a PV inverter comprising type \#1 power switches is installed in Murcia (Spain) and $L=1.682 \mathrm{mH}$ and $f_{s}=25.1 \mathrm{kHz}$, is shown in Fig. 6. 


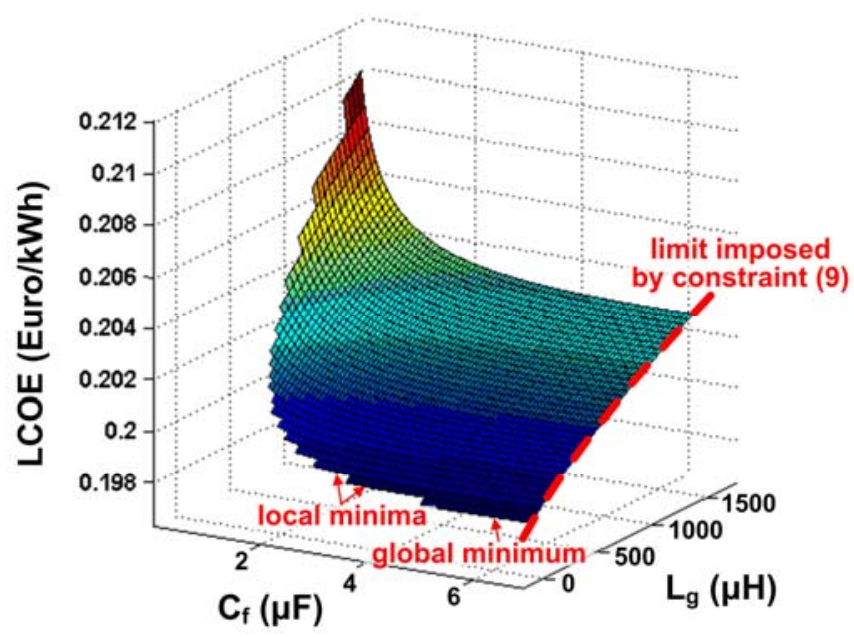

Fig. 6 The PV inverter LCOE versus the values of the decision variables $C_{f}$ and $L_{g}$ which satisfy the optimization problem constraints, in the case that a PV inverter comprising type \#1 power switches is installed in Murcia (Spain) and $L=1.682 \mathrm{mH}, f_{s}=25.1 \mathrm{kHz}$.

This diagram has been constructed using only the values of $C_{f}$ and $L_{g}$ which satisfy the optimization problem constraints. It is observed that the $L C O E$ function is highly non-linear and exhibits multiple local minima, thus dictating the use of a computationally efficient optimization algorithm, such as GAs, in order to derive the global optimum values of $C_{f}$ and $L_{g}$ which minimize the PV inverter $L C O E$.

\section{Conclusions}

The transformerless PV inverters are the major functional units of modern grid-connected PV energy production systems. In this paper, a systematic design process for the optimal design of transformerless PV inverters has been presented. The proposed method embraces optimization at both the converter-circuit and the circuit-device levels, using information about the solar irradiation potential of the PV installation site and the limitations imposed by the electric-grid-interconnection regulations. The design optimization results demonstrate that in sharp contrast to the non-optimized PV inverters designed using conventional techniques, where the installation-area-specific meteorological conditions are not considered during the design process, the PV inverter structures derived using the proposed methodology exhibit lower $L C O E$ and manufacturing cost, while 
simultaneously are capable of injecting more PV generated energy into the electric grid. Thus, by installing the PV inverters, which have been optimally designed using the proposed design optimization methodology considering both design and operation parameters, the earnings achieved by the installed PV capacity are increased.

\section{References}

[1] Kerekes, T., Teodorescu, R., Rodríguez, P., Vázquez, G., and Aldabas, E.,: 'A new highefficiency single-phase transformerless PV inverter topology', IEEE Transactions on Industrial Electronics, Vol. 58, No. 1, pp. 184-191, Jan. 2011.

[2] Xiao, H.F., Xie, S.J., Yang, C., and Huang, R.H.: 'An optimized transformerless photovoltaic grid-connected inverter', IEEE Transactions on Industrial Electronics, Vol. 58, No. 5, pp. 18871895, May 2011.

[3] Blaabjerg, F., Iov, F., Kerekes, T., and Teodorescu, R.: 'Trends in power electronics and control of renewable energy systems'. 14 ${ }^{\text {th }}$ International Power Electronics and Motion Control Conference (EPE/PEMC), pp. 1-19, 2010.

[4] Cha, H., and Vu, T.-K.: 'Comparative analysis of low-pass output filter for single-phase gridconnected Photovoltaic inverter'. $201025^{\text {th }}$ Annual IEEE Applied Power Electronics Conference and Exposition (APEC), pp. 1659-1665, 2010.

[5] Guerrero, J.M., Blaabjerg, F., Zhelev, T., Hemmes, K., Monmasson, E., Jemei, S., Comech, M.P., Granadino, R., and Frau, J.I.: 'Distributed Generation: toward a new energy paradigm', IEEE Industrial Electronics Magazine, Vol. 4 , Issue 1, pp. 52-64, March 2010.

[6] Pai, F.S., Chao, R.M., Ko, S.H., and Lee, T.S.: 'Performance Evaluation of Parabolic Prediction to Maximum Power Point Tracking for PV Array', IEEE Transactions on Sustainable Energy, Vol. 2, No. 1, pp. 60-68, Jan. 2011.

[7] Ma, L., Jin, X., Kerekes, T., Liserre, M., Teodorescu, R., and Rodriguez, P., 'The PWM strategies of grid-connected distributed generation active NPC inverters'. IEEE Energy Conversion Congress and Exposition (ECCE), pp. 920-927, 2009. 
[8] Hassan, M.A., and Abido, M.A., 'Optimal Design of Microgrids in Autonomous and GridConnected Modes Using Particle Swarm Optimization', IEEE Transactions on Power Electronics, Vol. 26, No. 3, pp. 755-769, March 2011.

[9] Fortunato, M., Giustiniani, A., Petrone, G., Spagnuolo, G., and Vitelli, M.: 'Maximum Power Point Tracking in a One-Cycle-Controlled Single-Stage Photovoltaic Inverter', IEEE Transactions on Industrial Electronics, Vol. 55, No. 7, pp. 2684-2693, July 2008.

[10] Koutroulis, E., and Blaabjerg, F.: 'Design Optimization of Grid-Connected PV Inverters'. $26^{\text {th }}$ Annual IEEE Applied Power Electronics Conference \& Exposition (APEC), pp. 691-698, 2011.

[11] Vazquez, G., Kerekes, T., Rolan, A., Aguilar, D., Luna, A., and Azevedo, G.: 'Losses and CMV evaluation in transformerless grid-connected PV topologies'. IEEE International Symposium on Industrial Electronics, pp. 544-548, 2009.

[12] Kjaer, S.B., and Blaabjerg, F.: 'Design optimization of a single phase inverter for photovoltaic applications'. 34 ${ }^{\text {th }}$ Annual IEEE Power Electronics Specialist Conference (PESC), Vol. 3, pp. 1183-1190, 2003.

[13] Kashihara, Y., and Itoh, J.: 'Parameter design of a five-level inverter for PV systems'. IEEE $8^{\text {th }}$ International Conference on Power Electronics and ECCE Asia (ICPE \& ECCE), pp. 1886$1893,2011$.

[14] Zeng, G., Rasmussen, T.W., and Teodorescu, R., 'A novel optimized LCL-filter designing method for grid connected converter'. $2^{\text {nd }}$ IEEE International Symposium on Power Electronics for Distributed Generation Systems (PEDG), pp. 802-805, 2010.

[15] Channegowda, P., and John, V.: 'Filter Optimization for Grid Interactive Voltage Source Inverters', IEEE Transactions on Industrial Electronics, Vol. 57 , No. 12, pp. 4106-4114, Dec. 2010.

[16] Lin, C. H., Hsieh, W. L., Chen, C. S., Hsu, C. T., and Ku, T. T.: 'Optimization of Photovoltaic Penetration in Distribution Systems Considering Annual Duration Curve of Solar Irradiation', IEEE Transactions on Power Systems, Vol. 27, No. 2, pp. 1090-1097, May 2012. 
[17] Kornelakis, A. and Koutroulis, E.: 'Methodology for the design optimisation and the economic analysis of grid-connected photovoltaic systems', IET Renewable Power Generation, Vol. 3, No. 4, pp. 476-492, 2009.

[18] Campbell, M., Blunden, J., Smeloff, E., and Aschenbrenner, P.: 'Minimizing utility-scale PV power plant LCOE through the use of high capacity factor configurations'. $34^{\text {th }}$ IEEE Photovoltaic Specialists Conference, pp. 421-426, 2009.

[19] Michalewicz, Z.: 'Genetic algorithms + data structures = evolution programs', Springer-Verlag, $2^{\text {nd }}$ Edition, 1994, pp. 15-18.

[20] Nge, C.L., Midtgard, O.-M., Norum, L., and Saetre, T.O.: 'Power loss analysis for single phase grid-connected PV inverters'. $31^{\text {st }}$ International Telecommunications Energy Conference, pp. 1$5,2009$.

[21] Liserre, M., Blaabjerg, F., and Hansen, S.: 'Design and control of an LCL-filter-based threephase active rectifier', IEEE Transactions on Industry Applications, Vol. 41, No. 5, pp. 12811291, Sept. 2005.

[22] Wei, X., Xiao, L., Yao, Z., and Gong, C.: 'Design of LCL filter for wind power inverter'. 2010 World Non-Grid-Connected Wind Power and Energy Conference (WNWEC), pp. 1-6, 2010.

[23] Kim, H., and Kim, K.-H.: 'Filter design for grid connected PV inverters'. IEEE International Conference on Sustainable Energy Technologies, pp. 1070-1075, 2008.

[24] Pattnaik, S.K., and Mahapatra, K.K.: 'Power loss estimation for PWM and soft-switching inverter using RDCLI'. International MultiConference of Engineers and Computer Scientists, pp. 1401-1406, 2010.

[25] Tadsuan, S., and Tangsiriworakul, C.: 'Design and comparison of iron losses mathematical model with single phase and three phase PWM inverter supply'. IEEE International Conference on Industrial Technology (ICIT), pp. 1-6, 2008.

[26] Tehrani, K.A., Rasoanarivo, I., and Sargos, F.-M.: 'Power loss calculation in two different multilevel inverter models (2DM2)', Electric Power Systems Research, Vol. 81, Issue 2, pp. 297-307, 2011. 
[27] Lorenzo, E.: 'Solar electricity - Engineering of photovoltaic systems', Progensa, $1^{\text {st }}$ Edition, 1994, pp. 87-99.

[28] Shimizu, T., and Iyasu, S.: 'A Practical Iron Loss Calculation for AC Filter Inductors Used in PWM Inverters', IEEE Transactions on Industrial Electronics, Vol. 56 , No. 7, pp. 2600-2609, July 2009.

[29] Chen, S., Peng, L., Brady, D., and Lehman, B.: 'Optimum inverter sizing in consideration of irradiance pattern and PV incentives'. $201126^{\text {th }}$ Annual IEEE Applied Power Electronics Conference and Exposition (APEC), pp. 982-988, 2011.

[30] Xue, Y., Divya, K.C., Griepentrog, G., Liviu, M., Suresh, S., and Manjrekar, M.: 'Towards next generation photovoltaic inverters', 2011 IEEE Energy Conversion Congress and Exposition (ECCE), pp. 2467-2474, 2011. 